\title{
Identification of a Neural Cell Specific Variant of Microtubule-Associated Protein 4
}

\author{
Kazuyuki Matsushima ${ }^{{ }^{*}}$, Masafumi Aosaki ${ }^{1}$, Kiyotaka Tokuraku², Mohammad Rubayet Hasan', \\ Hiroyuki Nakagawa ${ }^{1}$, and Susumu Kotani ${ }^{1,3}$ \\ ${ }^{1}$ Department of Bioscience and Bioinformatics, Faculty of Computer Science and Systems Engineering, \\ Kyushu Institute of Technology, Kawazu 680-4, Iizuka-shi, Fukuoka, 820-8502, Japan, ${ }^{2}$ Department of \\ Chemical Science and Engineering, Miyakonojo National College of Technology, Yoshio-cho 473-1, Miya- \\ konojo, Miyazaki 885-8567, Japan, and ${ }^{3}$ Department of Biological Sciences, Faculty of Science, Kanagawa \\ University, Tsuchiya 2946, Hiratsuka, Kanagawa 259-1293, Japan
}

\begin{abstract}
The microtubule-binding domain of MAP4, a ubiquitous microtubule-associated protein, contains a region rich in proline and basic residues (proline-rich region). We searched the bovine adrenal gland for MAP4 isoforms, and identified a novel variant lacking 72 consecutive amino acid residues within the proline-rich region, as compared with the full-length MAP4. The amino acid sequence of the missing region was highly conserved (about $85 \%$ identity/similarity) among the corresponding regions of bovine, human, mouse, and rat MAP4, which suggested the functional significance of this region. A comparison of the genomic sequence with the cDNA sequence revealed that the missing region is encoded by a single exon. A MAP4 variant cDNA homologous to the bovine form was also detected in rat cells, suggesting that the new variant can be generated by alternative splicing, not only in bovine but also in other mammalian species. The mRNA expression of the novel isoform was restricted to the brain and the adrenal medulla, suggesting that this isoform is specific to a certain cell type. Using a bacterially expressed fragment corresponding to the microtubule-binding domain of the novel isoform, we analyzed its in vitro characteristics. The fragment induced microtubule assembly and bound to preformed microtubules, but the activities were slightly lower than those of the conventional MAP4 fragment, which carries the fulllength proline-rich region. The microtubules assembled in the presence of the fragment failed to be bundled. Instead, a constant spacing between neighboring microtubules was observed.
\end{abstract}

Key words: microtubule-associated proteins/MAP4/MAP4 variant/neural cell specific/proline-rich/microtubule bundling

\section{Introduction}

In eukaryotic cells, microtubules are essential for various

\footnotetext{
*To whom correspondence should be addressed: Kazuyuki Matsushima, Department of Bioscience and Bioinformatics, Faculty of Computer Science and Systems Engineering, Kyushu Institute of Technology, Kawazu 680-4, Iizuka-shi, Fukuoka, 820-8502, Japan.

Tel: +81-948-29-7840, Fax: +81-948-29-7801

E-mail: a791011k@bse.kyutech.ac.jp

Abbreviations: MAP(s), microtubule-associated protein(s); Pro-rich, proline rich; AP sequence, assembly-promoting sequence; NGF, nerve growth factor; bp, base pair; $100 \mathrm{MEM}$, reassembly buffer consisting of $100 \mathrm{mM}$ 2-(N-morpholino) ethanesulfonic acid ( $\mathrm{pH} 6.8), 0.5 \mathrm{mM} \mathrm{MgSO}_{4}, 0.1 \mathrm{mM}$ EGTA; PAGE, polyacrylamide gel electrophoresis; MAP4-LP, MAP4 isoform with long Pro-rich region; MAP4-SP, MAP4 isoform with short Pro-rich region.

The term "protomer" refers to a unit of the polymerization reaction. In microtubule assembly, the tubulin dimer is the protomeric unit. When we discuss the assembly process, we use this term, rather than "heterodimer" or "monomer", to avoid confusion.
}

cellular functions, such as mitosis, intracellular transport, and determination of the cell shape (Dustin, 1984). Several kinds of microtubule-associated proteins (MAPs) ${ }^{1}$ have been identified as accessory proteins that can bind to the surface of microtubules. As MAPs not only promote the assembly of microtubules but also stabilize them in vitro, they are believed to play important roles in the regulation of microtubule formation and stabilization in vivo.

MAPs are categorized into neural MAPs and non-neural MAPs, based on their cellular expression patterns. Among the non-neural MAPs, the biochemical characteristics of MAP4 are the most widely known (see Tokuraku et al., 2002 for review). Studies of the primary structure of MAP4 have revealed that it is structurally similar to the neural MAPs, MAP2 and tau, with an N-terminal projection domain and a C-terminal microtubule-binding domain (Lewis et al., 1988; Kindler et al., 1990; Kalcheva et al., 1995; Drubin et al., 1984; Goedert et al., 1988; Lee et al., 
1988; Himmler et al., 1989; Andreadis et al., 1992). In these three MAPs, the microtubule-binding domain can be roughly divided into three subdomains: a region rich in proline and basic residues (Pro-rich region), a region with a tandem organization of the homologous sequence (Assembly-Promoting (AP) sequence) responsible for promoting microtubule assembly (Repeat region), and a short tail region with hydrophobic and acidic residues (Tail region).

The function of the Pro-rich region as well as that of the Repeat region is essential for MAP4 to promote microtubule assembly (Katsuki et al., 1997; Tokuraku et al., 1999a), whereas the Tail region cannot directly interact with microtubules (Katsuki et al., 1999). The Pro-rich region and the Repeat region are rich in basic residues and are thought to interact with the acidic C-terminus of tubulin, the unit molecule of microtubules. We have previously shown that the nucleation process of microtubule assembly depends on the activity of the Pro-rich region, rather than that of the Repeat region (Tokuraku et al., 1999a). Furthermore, the phosphorylation of the Pro-rich region negatively regulates the MAP4 promotion of microtubule assembly (Ookata et al., 1997). These studies indicate that the Pro-rich region is important in stimulating microtubule assembly, and in regulating MAP4 function.

Cellular MAP4 molecules exist as several alternatively spliced variants, with 3 to 5 different AP sequence repeats (Tokuraku et al., 2003; West et al., 1991; Chapin et al., 1995). Many investigators have studied the Repeat region variations of MAPs, since this region is considered to be essential for their function (Tokuraku et al., 1999b, 2002; Lewis et al., 1988; Lee et al., 1988). Four MAP4 cDNA clones with different Repeat region organizations have been identified from bovine (Tokuraku et al., 2003), human (West et al., 1991; Chapin et al., 1995), and mouse (West et al., 1991) sources. We have shown that these four MAP4 variants are expressed simultaneously in the bovine adrenal gland (Tokuraku et al., 2003). Although the Pro-rich region encompasses over half of the microtubule-binding domain, MAP4 isoforms with Pro-rich region variations have not been reported. Since the Pro-rich region, as well as the Repeat region, is important for the function of MAPs, it is possible that MAPs regulate their functions by producing different isoforms of the Pro-rich region. As for tau, a cDNA for the chicken brain tau isoform, which contains an insert in the Pro-rich region, has recently been isolated and characterized (Yoshida and Goedert, 2002). Characterizations of MAP4 variants with different Pro-rich region organizations may be helpful in understanding the regulation of MAP4 function.

In this study, we demonstrated the existence of a bovine MAP4 transcript/protein containing a deletion within the Pro-rich region. In addition to bovine tissues, the rat version of the new variant was also detected in PC12 (rat pheochromocytoma) cells and rat brain tissue. The expression of this variant in PC12 cells increased upon nerve growth factor
(NGF)-induced differentiation. The in vitro characterization of the new isoform revealed that the deletion slightly affects the assembly promoting activity of MAP4. The new isoform failed to bundle microtubules.

\section{Materials and Methods}

\section{Materials}

Taxol was generously supplied by Dr. N. Lomax, of the Natural Products Branch, National Cancer Institute, Bethesda, MD. It was dissolved in dimethyl sulfoxide to a stock concentration of $1 \mathrm{mM}$ and was stored at $-20^{\circ} \mathrm{C}$. Taq DNA polymerase (Ex Taq) was purchased from Takara Shuzo Co. Ltd. (Tokyo, Japan). Oligonucleotides were purchased from Hokkaido System Science (Sapporo, Japan). Sources of other materials are given in the text. All chemicals were of reagent grade unless otherwise mentioned.

\section{Cell culture}

The rat pheochromocytoma cell line, $\mathrm{PC} 12$, and the rat embryonic fibroblast cell line, $3 \mathrm{Y} 1$, were grown as described previously (Nakagawa and Miyamoto, 1998; Nakagawa et al., 2000). For the differentiation of PC12 cells, NGF was added (final concentration, $50 \mathrm{ng} / \mathrm{ml}$ ) to the cell cultures.

\section{DNA sequencing}

For the sequencing reactions of the bovine and rat MAP4 cDNAs, the plasmids bearing the PCR products were prepared by the alkaline lysis method (Sambrook et al., 1989). DNA sequencing of the purified double-stranded plasmid DNA was performed by the dideoxy chain-termination method (Sanger et al., 1977), using a Thermosequenase fluorescent-labeled primer cycle sequencing kit (Amersham Pharmacia Biotech). The nucleotide sequences were obtained by electrophoresis, using a DSQ-1000 DNA sequencer (Shimadzu, Kyoto, Japan). The data for the MAP4 clones were derived from sequencing on both strands and for many regions, by the sequencing of multiple overlapping clones. The reading frame for the rat MAP4 clones was assigned by comparisons of its sequences with those published for the bovine (Aizawa et al., 1990), mouse, and human (West et al., 1991) MAP4.

\section{RNA purification}

Total cellular RNA was isolated from adult bovine tissues, rat cells, and rat brain by the method of Chomczynski and Sacchi (1987). Since the bovine adrenal gland used in this study contained both the adrenal cortex and medulla, the medulla was carefully separated from the cortex with a surgical blade, to prepare the adrenal cortex RNA and medulla RNA separately. For RNA purification from cultured cells, the medium was removed, and the cells were washed twice with ice-cold phosphate-buffered saline. The cells were lysed by adding cold lysis buffer ( $5 \mathrm{M}$ guanidinium 
thiocyanate, $10 \mathrm{mM}$ EDTA, $50 \mathrm{mM}$ Tris ( $\mathrm{pH} 7.5)$, and $8 \%(\mathrm{v} / \mathrm{v})$ 2-mercaptoethanol) directly to the dish, and the total RNA was isolated as described above.

\section{RT-PCR (reverse transcription-polymerase chain reaction)}

The RNAs from the adult bovine tissues were reverse-transcribed with an oligo $(\mathrm{dT})_{18}$ primer and recombinant Moloney-Murine leukemia virus reverse transcriptase (GIBCO/BRL, Tokyo, Japan), according to the manufacturer's instructions. We designed the following PCR primers, based on the bovine MAP4 sequence (DDBJ/ EMBL/GenBank Accession Number D90149), so that they would specifically amplify the cDNAs for the Pro-rich region of bovine MAP4: P1-f (nucleotides 1630-1646 from the bovine MAP4 cDNA sequence (Aizawa et al., 1990)); P1-r (nucleotides 26112628); P2-f (nucleotides 1677-1696); P2-r (nucleotides 22282247). To amplify the cDNAs for the Pro-rich region, we used primer set \#1 (P1-f and P1-r), spanning a 999-bp portion of the MAP4 cDNA between bases 1630 and 2628. Thermal cycles included a 2 -min denaturation step $\left(94^{\circ} \mathrm{C}\right)$, followed by 30 cycles consisting of $94^{\circ} \mathrm{C}$ (denaturation, $30 \mathrm{~s}$ ), $57^{\circ} \mathrm{C}$ (annealing, $30 \mathrm{~s}$ ), and $72^{\circ} \mathrm{C}$ (primer extension, $90 \mathrm{~s}$ ). To detect the PCR products more efficiently than in the experiment with primer set \#1, we used primer set \#2 (P2-f and P2-r), which spanned a 571-bp portion of the cDNA between bases 1677 and 2247. The PCR program included $2 \mathrm{~min}$ at $94^{\circ} \mathrm{C}$ for 1 cycle, followed by 30 cycles of $94^{\circ} \mathrm{C}$ for $30 \mathrm{~s}, 59^{\circ} \mathrm{C}$ for $30 \mathrm{~s}$, and $72^{\circ} \mathrm{C}$ for $1 \mathrm{~min}$. To amplify the cDNAs for the entire microtubule-binding domain of bovine MAP4, we used an additional primer set, primer set \#3 (P1-f and T1-r with the sequence of 5'-GCG AAT TCA TTA GAT GCT TGT CTC CTG G-3' (nucleotides 3279-3300)), spanning a 1671-bp portion of the MAP4 cDNA between bases 1630 and 3300. The 5'-GCG AAT of the T1-r is not derived from the MAP4 sequence, but was added for subcloning in an expression plasmid. The PCR program included $2 \mathrm{~min}$ at $94^{\circ} \mathrm{C}$ for 1 cycle, followed by 30 cycles of $94^{\circ} \mathrm{C}$ for $30 \mathrm{~s}$ and $59^{\circ} \mathrm{C}$ for $30 \mathrm{~s}$, and $72^{\circ} \mathrm{C}$ for $2 \mathrm{~min}$. PCR products were electrophoresed on a $1 \%$ agarose gel, and the bands were detected using ethidium bromide. The PCR products were subcloned into the pT7Blue T-vector (Novagen) as described (Tokuraku et al., 2003). Sequences were confirmed by complete sequencing of both DNA strands of each clone. Since rat MAP4 cDNA sequences are not available, we used the mouse MAP4 sequence (West et al., 1991) to amplify the rat Pro-rich region cDNA, and designed two PCR primers (nucleotides 2421-2441 and 2970-2989), spanning a 569-bp portion of the mouse MAP4 cDNA between bases 2421 and 2989. The thermal cycle included a 2-min denaturation step $\left(94^{\circ} \mathrm{C}\right.$ ), followed by 30 cycles consisting of $94^{\circ} \mathrm{C}$ (denaturation, 30 s), $54^{\circ} \mathrm{C}$ (annealing, $30 \mathrm{~s}$ ), and $72^{\circ} \mathrm{C}$ (primer extension, $60 \mathrm{~s}$ ). We ascertained that these primers can amplify the rat MAP4 cDNAs by subcloning and sequencing the amplified rat MAP4 cDNA bands described above. The quantities of the PCR products from rat cDNA were measured by using computer imaging software (Scion Image 1.62; Scion Corp, Frederick, MD, USA), with the resultant plot profile and the peak values.

\section{Analysis of exon/intron junctions}

Total bovine genomic DNA was prepared from adult bovine liver by the procedure based on treatments with proteinase $\mathrm{K}$ and ribonuclease A (Sambrook et al., 1989). Afterward, the DNA fraction was purified by repeated phenol and phenol-chloroform extractions (Lazo, 1988). Since the region missing in the new isoform (encoding amino acid residues 650-721) matched the human MAP4's exon 10 (amino acid residues 703-774; see (West et al., 1991 ) for sequence), we tentatively named it "exon 10". To clarify the genomic sequence of the bovine MAP4 gene in the vicinity of "exon 10", we designed primer set \#4, P3-f (nucleotides 19111929 from the bovine MAP4 cDNA sequence (Aizawa et al., 1990)) and P3-r (nucleotides 1966-1986); and primer set \#5, P4-f (nucleotides 2000-2020) and P2-r. PCR reactions were carried out in $100 \mu \mathrm{l}$ reaction mixtures consisting of $100 \mathrm{ng}$ of genomic DNA, 10 pmol of primer set \#4 or \#5, 0.5 units of Ex Taq polymerase, and buffer supplied by the manufacturer. After an initial denaturation step for $2 \mathrm{~min}$ at $94^{\circ} \mathrm{C}$, amplifications were performed for 30 cycles $\left(94^{\circ} \mathrm{C}\right.$ for $30 \mathrm{~s}, 59^{\circ} \mathrm{C}$ for $30 \mathrm{~s}, 72^{\circ} \mathrm{C}$ for $6 \mathrm{~min}$ per cycle). PCR products from each reaction were subcloned, and their sequences were determined by sequencing both DNA strands of each clone.

\section{Construction of expression plasmids for the MAP4 isoform fragment}

To construct an expression plasmid for the SP fragment (containing the microtubule-binding domain of the new isoform), the plasmid containing the PCR product, encoding the microtubulebinding domain of the new isoform, was cleaved with $N c o$ I and EcoRI. The $N c o I / E c o R I$ end cDNA fragment was purified and ligated in-frame into the expression plasmid vector pET21d(+) (Stratagene, La Jolla, CA), which had been treated with the same enzymes. The resultant plasmid encodes the microtubule-binding domain of the new isoform (amino acid residues 579-1026; Fig. $4 a)$. Construction of the expression plasmid for the microtubulebinding domain of intact MAP4 (amino acid residues 579-1098, named the LP fragment in this paper) was described previously (Tokuraku et al., 2003). Both constructs were designed in such a way that the translation starts at an internal methionine codon and ends at the stop codon of the original MAP4 sequence without expressing the his-tag of pET21d(+) vector. To avoid the redundancy of methionine residues at the $\mathrm{N}$-terminus, translation frames were adjusted with the vector sequence to encode a single methionine residue at the beginning. Therefore, each plasmid expresses the MAP4 fragment without any additional sequences at the $\mathrm{N}$ - or C-terminal end.

\section{Preparation of antibodies and immunoblotting}

The rabbit anti-(Pro-rich region) antiserum was obtained as described previously (Kotani et al., 1986) using a recombinant bovine MAP4 fragment containing the Pro-rich region (residues 647-866) (Tokuraku et al., 1999a). Immunoblottings were per- 
formed as described (Tokuraku et al., 1999b) with the anti-(Prorich region) antiserum at 1:3000 dilution. To obtain antibodies specific to a part of the Pro-rich region (residues 647-866), $1 \mu \mathrm{l}$ of the anti-(Pro-rich region) antiserum was incubated with $200 \mu \mathrm{l}$ of the purified SP fragment $(5 \mathrm{mg} / \mathrm{ml})$, in $3 \%$ bovine serum albumin in phosphate-buffered saline, for $16 \mathrm{hrs}$ at $4^{\circ} \mathrm{C}$. Complexes composed of antibodies and the SP fragment in the mixture were removed by centrifugation at $16,000 \mathrm{~g}$ for $30 \mathrm{~min}$ at $4^{\circ} \mathrm{C}$. The supernatant (the pre-absorbed anti-(Pro-rich region) antiserum), which contains antibodies that recognize residues 647-866 of the Pro-rich region, was reactive to the LP fragment, but not to the SP fragment (see Fig. 4b, for results). The pre-absorbed antiserum was used at 1:5 dilutions.

\section{Preparation of proteins}

Microtubule protein was prepared from bovine brains by two cycles of temperature-dependent polymerization/depolymerization (Shelanski et al., 1973). Tubulin was purified from the twicecycled microtubule protein fractions by phosphocellulose column chromatography (Weingarten et al., 1975), and was stored at $-80^{\circ} \mathrm{C}$. The recombinant plasmids for the SP fragment and the LP fragment were each transformed into Escherichia coli BL21(DE3)pLysS (Stratagene, La Jolla, CA). The SP fragment was expressed and purified by the same method as for the LP fragment (Tokuraku et al., 2003).

Heat-stable fractions of the bovine adrenal tissues were prepared as described previously (Kotani et al., 1986) with modifications. Briefly, the adult bovine adrenal cortex and the medulla were each homogenized in 5 volumes of 100 MEM buffer (100 $\mathrm{mM}$ 2-(N-morpholino) ethanesulfonic acid ( $\mathrm{pH} 6.8), 0.1 \mathrm{mM}$ EGTA, and $0.5 \mathrm{mM} \mathrm{MgSO}_{4}$ ) containing $1 \mathrm{mM}$ phenylmethylsulfonyl fluoride, and centrifuged at $40,000 \mathrm{~g}$ for $30 \mathrm{~min}$ at $2{ }^{\circ} \mathrm{C}$. The supernatant was incubated at $100^{\circ} \mathrm{C}$ for $5 \mathrm{~min}$ in the presence of $0.8 \mathrm{M} \mathrm{NaCl}$ and $1 \%(\mathrm{v} / \mathrm{v})$ 2-mercaptoethanol, and was clarified by centrifugation. The supernatant was dialyzed against the buffer, mixed with 4 volumes of acetone, and stirred for $30 \mathrm{~min}$. The precipitated proteins were collected by centrifugation, dissolved in electrophoresis sample buffer containing sodium dodecyl sulfate, and boiled for $5 \mathrm{~min}$.

Protein concentrations were determined by the method of Lowry et al. (1951), using bovine serum albumin as the standard. Sodium dodecyl sulfate-polyacrylamide gel electrophoresis (SDSPAGE) was carried out according to Laemmli (1970). Gels were stained with Coomassie Brilliant Blue R250.

\section{Measurements of microtubule assembly and MAP-microtubule binding}

Microtubule assembly under taxol-free conditions was monitored by measuring either the change in absorbance at $350 \mathrm{~nm}$ or the amount of polymerized tubulin, as described previously (Katsuki et al., 1997). The MAP4 fragments and tubulin were mixed at $0^{\circ} \mathrm{C}$ in 100 MEM buffer containing $0.5 \mathrm{mM}$ GTP. Microtubule assembly was initiated by raising the temperature from $0^{\circ} \mathrm{C}$ to $37^{\circ} \mathrm{C}$.
Binding of MAP4 isoform fragments to taxol-stabilized microtubules was analyzed as described previously (Tokuraku et al., 1999a). The Scatchard analysis (Scatchard, 1949) was performed according to Coffey and Purich (1995). The apparent dissociation constant $\left(K_{d}\right)$ and the limit stoichiometry between the MAP fragment and tubulin protomer were calculated from the slope and the intercept, respectively, as determined by linear regression.

\section{Electronmicroscopy}

To prepare microtubule samples for the morphological observations, $1 \mu \mathrm{M}$ or $15 \mu \mathrm{M}$ of MAP4 isoform fragments and $10 \mu \mathrm{M}$ or $15 \mu \mathrm{M}$ of tubulin were mixed at $0^{\circ} \mathrm{C}$ in $100 \mathrm{MEM}$ buffer containing $0.5 \mathrm{mM} \mathrm{GTP}$, and incubated for $10 \mathrm{~min}$ at $37^{\circ} \mathrm{C}$ under taxolfree conditions. To obtain taxol-stabilized microtubules, $15 \mu \mathrm{M}$ of tubulin were mixed in the buffer containing $15 \mu \mathrm{M}$ taxol. Negative staining observations and thin section observations were performed as described previously (Tokuraku et al., 1999a). To determine the inter-microtubule distances, more than 200 microtubules were chosen at random, and the wall-to-wall distance of each microtubule to its nearest neighbor was measured directly. Another method based on Iida et al. (2002) was also performed, where the center-to-center distances of two neighboring microtubules were measured and the diameter of the microtubule (25 $\mathrm{nm})$ was subtracted from the center-to-center distances.

\section{Results}

\section{Identification of a MAP4 with a variation in the Pro-rich region}

To identify whether any splicing variants of MAP4 with shorter Pro-rich regions exist, we first amplified bovine adrenal cDNAs encoding the MAP4 Pro-rich region by the reverse transcription (RT)-PCR technique, using the MAP4 specific primer set \#1 (Fig. 1a). As shown in Fig. 1b (lane 2), a prominent band of approximately 800 bp was amplified along with a 999 bp band, which corresponded to the conventional MAP4 transcript (lane 6). We then subcloned the 800 bp band into the plasmid vector; twelve subcloned plasmids were isolated (data not shown) and sequenced. All of the isolated plasmids encoded a part of the MAP4 coding region with an internal $216 \mathrm{bp}$ deletion in common. The reading frame was maintained, and the resulting protein product lacked an internal subdomain of 72 amino acids, which corresponded to amino acid residues 650-721 (Fig. 1c). Since the deletion is located in the Pro-rich region, we named the new isoform MAP4-SP (short Pro-rich) and renamed the original MAP4 as MAP4-LP (long Pro-rich). We compared the amino acid sequence of MAP4-SP with those of other MAP4 isoforms in the GenBank ${ }^{\mathrm{TM}}$ database, and found that no analogous variants had been submitted thus far.

The genomic human MAP4 sequence (GenBank Acces- 


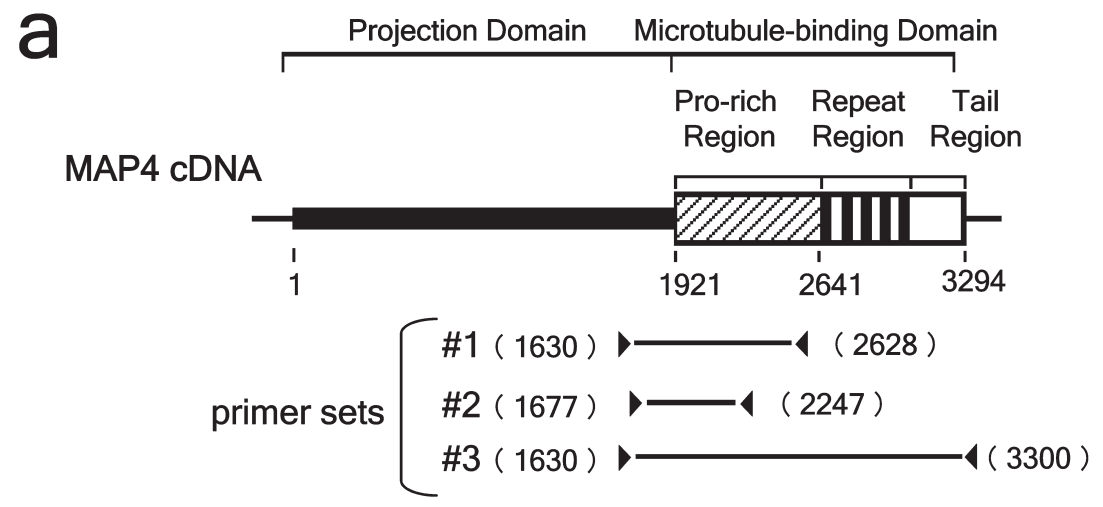

b

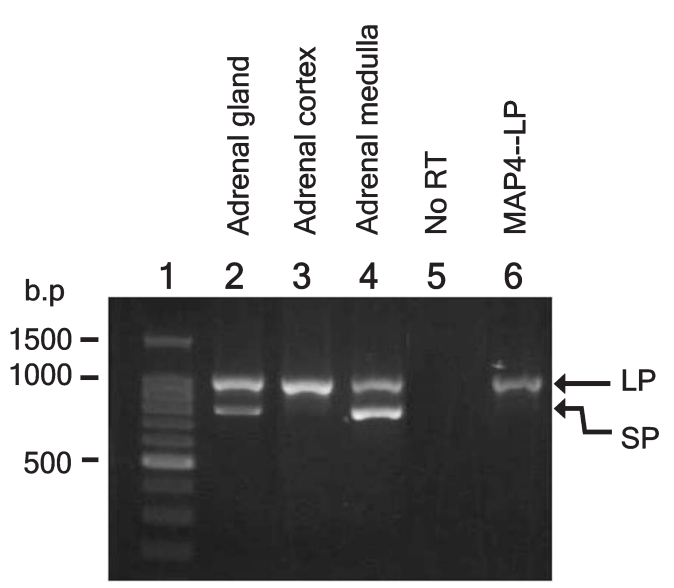

C

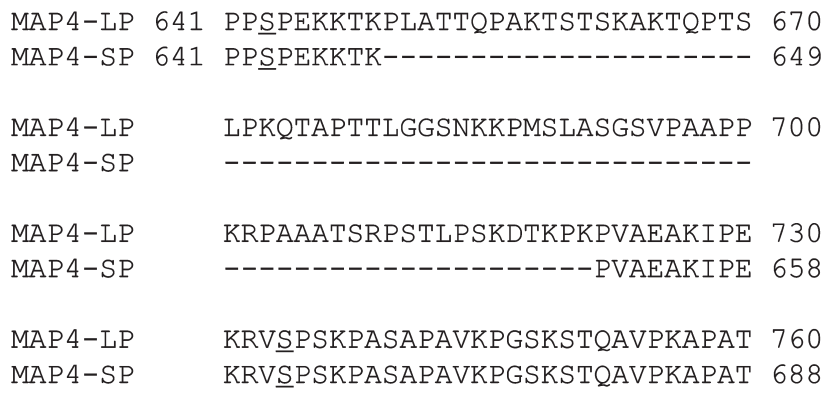

Fig. 1. Identification of a new MAP4 transcript in bovine adrenal tissues. a, schematic presentation of the bovine MAP4 cDNA structure and the primers used in this study. Arabic numerals represent the nucleotide sequence numbers starting from the initiation codon (Aizawa et al., 1990). The coding regions for the projection domain, the Pro-rich region, the AP sequences of 18 amino acid residues in the Repeat region, and the Tail region are indicated by a filled thin box, a shaded thick box, filled thick boxes, and an open thick box, respectively. Three MAP4 specific primer sets (\#1-\#3) were designed to amplify the regions of the MAP4 cDNAs indicated by lines, with the six primers indicated by arrowheads. The numbers in parentheses indicate the base-pair from which the primings would start. b, agarose gel electrophoresis of the RT-PCR products after 30 cycles of amplification. RNAs prepared from the bovine adrenal gland (lane 2), the adrenal cortex (lane 3), and the adrenal medulla (lane 4) were reverse-transcribed and then amplified with primer set \#1. Molecular weight markers (100 bp DNA ladder, Takara, Tokyo, Japan) are shown in lane 1. Lane 5 is a control experiment, showing the lack of a PCR product in the absence of the reverse transcriptase. Lane 6 is a 999 bp marker amplified from a plasmid containing the cDNA for MAP4-LP (Tokuraku et al., 2003), using primer set \#1. Arrows indicate the mobilities of the PCR products in lanes 2, 3, and 4. c, comparison of the deduced partial amino acid sequences of the Pro-rich regions of MAP4-SP and MAP4-LP. The sequence for MAP4-LP is derived from the published data of Aizawa et al. (1990). Dashes indicate the 72 amino acids missing from MAP4-SP. Underlined serine residues (Ser-643 and Ser-734) correspond to Ser-696 and Ser-787 in human MAP4, which are $\mathrm{p} 34^{\mathrm{cdc} 2}$ kinase phosphorylation sites (Ookata et al., 1997). The nucleotide sequence of the cDNA encoding the microtubule-binding domain of MAP4-SP is available under the DDBJ/EMBL/GenBank Accession Number AB100953. 
sion Number NT005825) showed that the human MAP4 gene consists of at least 19 exons. Among them, exon 10 completely matches the nucleotide sequence missing in the MAP4-SP mRNA. Although the genomic bovine MAP4 sequence is unknown, we considered the missing subdomain to be a bovine version of exon 10 , and tentatively call it "exon 10" in this study. To identify the downstream and upstream sequences of "exon 10" in the bovine MAP4 gene, we designed primer sets \#4 and \#5 (Fig. 2a), and performed genomic PCR experiments (Fig. 2). The human MAP4 exon 10 is located between upstream $(<1.5 \mathrm{kbp})$ and downstream $(<3.5 \mathrm{kbp})$ introns, and we obtained PCR products of approximately $0.7 \mathrm{kbp}$ and $2.5 \mathrm{kbp}$ (data not shown). We then determined the nucleotide sequences of the PCR products, and identified the exon-intron boundaries by comparing the sequences of the cDNA and genomic PCR products (Fig. 2b). As expected, the two introns were located down- stream and upstream of bovine "exon 10": one is between amino acid residues 649 and 650, and the other is between 721 and 722. The positions of the bovine introns were the same as those of the human. In addition, each of the donor and acceptor splicing sites conformed to the so-called GTAG rule (Jacob and Gallinaro, 1989). Based on the intronexon structure, "exon 10" was evidently skipped over to produce the mRNA variant encoding MAP4-SP.

We prepared the adrenal cortex and medulla RNAs separately, and then tested them for the expression of the MAP4-SP mRNA. PCR products encoding MAP4-LP were detected in both tissues (Fig. 1b, lanes 3 and 4), while the band for MAP4-SP was detected only in the adrenal medulla (Fig. 1b, lane 4), despite the facts that the protein content of MAP4 is relatively high in the cortex (Kotani et al., 1986) and that we identified various MAP4 isoform mRNAs in both types of adrenal tissues (Tokuraku et al.,

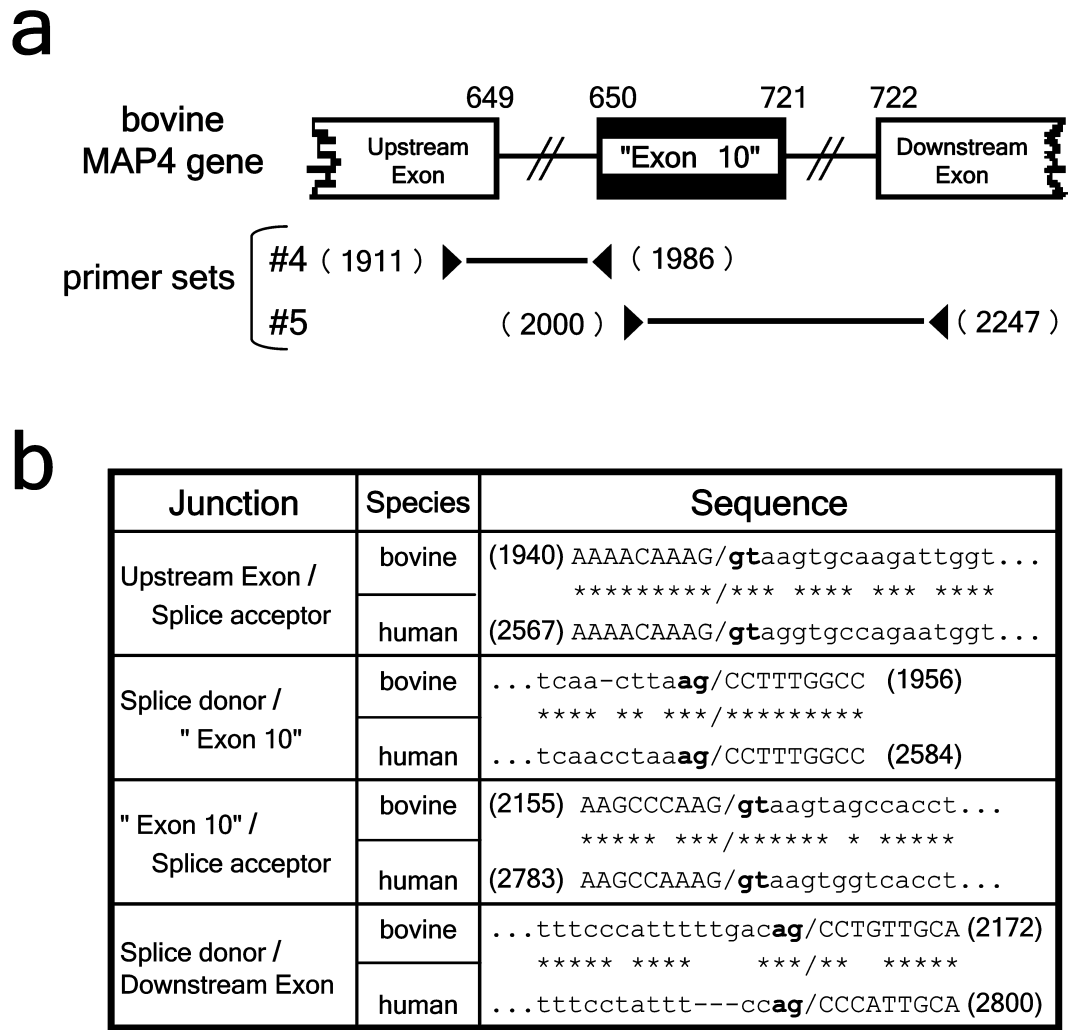

Fig. 2. Genomic organization of the bovine MAP4 Pro-rich region. a, partial schematic structures in the vicinity of the missing exon "exon 10" in MAP4SP mRNA. Exons are represented as boxes and introns as lines. The "exon 10" region is indicated by a filled box. Arabic numerals above exons indicate the amino acid residue numbers of bovine MAP4-LP. Two MAP4 specific primer sets (\#4-\#5) are shown below the gene structure, with the four primers indicated by arrowheads. These primer sets were designed to amplify the indicated exonic and intronic regions of the bovine MAP4 gene. The numbers in parentheses indicate the base-pair of the MAP4 coding region from which the primings would start. b, alignments of the partial genomic sequences of the bovine and human MAP4 gene (GenBank Accession Number NT_005825). The exon nucleotides of the bovine or human MAP4 gene are shown in uppercase letters, and the splice acceptor and donor sequences are shown in lowercase letters, with the GT and AG dinucleotides in bold-face type. The numbers in parentheses show the base-pair position of the bovine (Tokuraku et al., 2003) or human (West et al., 1991) MAP4 cDNA sequence numbers. Identical nucleotide sequences within bovine and human MAP4 are represented by an asterisk and deletions are indicated by a bar. The nucleotide sequences of the splice acceptor and donor sequences are available under the DDBJ/EMBL/GenBank Accession Numbers AB101642, AB101643, AB108687, and AB108688. 
2003). Sequencing of the higher mobility band showed that the sequence of the PCR product was identical to that of MAP4-SP (Fig. 1c).

\section{Tissue distribution of MAP4-SP $\mathrm{mRNA}$}

Full-length MAP4 mRNAs, and MAP4 isoform mRNAs with variations in the Repeat region, are ubiquitously detectable in various tissues (Tokuraku et al., 2003; Chapin et al., 1995). We tested the cellular expression patterns of the MAP4-SP mRNA using primer set \#2 (Fig. 1a), and found that it was expressed only in the adrenal medulla and brain (Fig. 3a). It should be emphasized that the expression patterns of the MAP4-SP transcript were distinct from those of the MAP4 isoforms with variations in the repeat region, which are ubiquitous (Tokuraku et al., 2003; Chapin et al., 1995). Since the adrenal medulla is derived from the neural
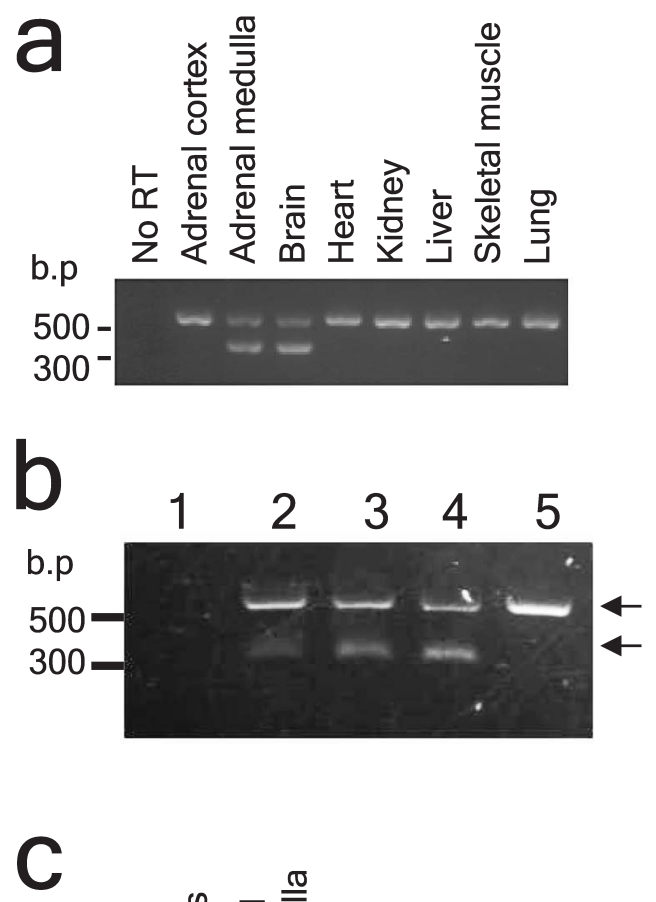

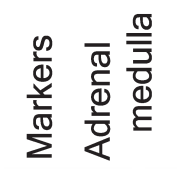

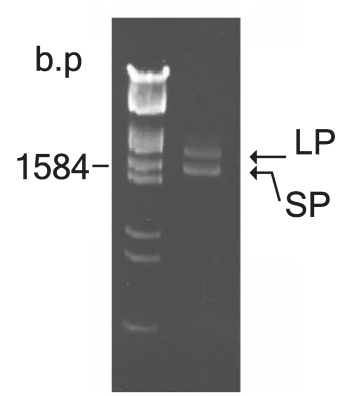

Fig. 3. crest, the expression of MAP4-SP mRNA may be related to neural tissue differentiation and/or function.

To examine this, another RT-PCR experiment was done using the RNAs prepared from PC12 pheochromocytoma cells (Fig. 3b), which are derived from the rat adrenal medulla and are widely used as a system for studying neuronal differentiation in response to nerve growth factor (NGF). Primers were designed according to the mouse MAP4 sequences, because no reliable rat MAP4 sequences were available in the GenBank ${ }^{\mathrm{TM}}$ database. As shown in Fig. $3 \mathrm{~b}$ lane 2, two PCR products of about $550 \mathrm{bp}$ and 350 bp were amplified. Sequencing revealed that the lower mobility band (569 bp) encoded a part of the rat MAP4-LP Pro-rich region, while the higher one (347 bp) encoded a rat MAP4 Pro-rich region with an internal deletion of 222 bp (74 amino acids) (data not shown). The amino acid sequence of the missing region was $97 \%$ identical to that of the corresponding region from the mouse, and the deletion occurred at the same position as that of bovine MAP4-SP. The $347 \mathrm{bp}$ band was considered to be derived from the rat version of MAP-SP mRNA. The $347 \mathrm{bp}$ band was reproducibly detected as one of the predominant species in rat brain (lane 4), while it was absent in 3Y1 (rat embryonic fibroblast) cells (lane 5). The sequences of the higher and lower molecular mass bands in the brain sample were identical to the PC12 569 bp and 347 bp bands, respectively. The expression of MAP4-SP was slightly increased when the PC12 cells were allowed to differentiate in the presence of NGF (lane 3): the peak ratios of the 347/569 bp bands in lanes 2 and 3 were 0.75 and 0.85 , respectively.

Fig. 3. RT-PCR analysis of MAP4-SP expression. In a-c, the RT-PCR products after 30 cycles of amplification were separated by agarose electrophoresis. a, tissue-specific expression of MAP4-SP. The RT-PCR was carried out with the MAP4 specific primer set \#2 (Fig. 1a) and with total RNA prepared from various bovine tissues. In the experiment using primer set \#2, two PCR products, $568 \mathrm{bp}$ and $352 \mathrm{bp}$, would be amplified from the cDNAs for MAP4-LP and MAP4-SP, respectively. The $568 \mathrm{bp}$ band was detected in all RNA samples tested, while the $352 \mathrm{bp}$ band was amplified only in the adrenal medulla and brain. The lane "No RT" shows a control experiment in the absence of the reverse transcriptase. $b$, detection of a rat version of the MAP4-SP cDNAs. The primers were designed to amplify rat MAP4 cDNAs encoding a part of the Pro-rich region, as described in the "Materials and Methods". The RT-PCR was performed with primers and total RNA prepared from the following sources: lanes 1 and 2, PC 12 cells; lane 3, PC 12 cells treated with NGF; lane 4, rat brain; lane 5, 3Y1 cells. Lane 1 is a control experiment in the absence of the reverse transcriptase. The mobilities of the PCR products encoding MAP4-LP and MAP4-SP are shown by arrows. The nucleotide sequences of the two bands, which encoded partial sequences of rat MAP4-LP and MAP4-SP, are available under the DDBJ/EMBL/GenBank Accession Numbers AB175782 and AB175783, respectively. c, amplification of bovine MAP4-SP cDNAs encoding the entire microtubule-binding domain. The RT-PCR was carried out with the MAP4 specific primer set \#3 (Fig. 1a) and total RNA prepared from bovine adrenal medulla. Primer set \#3 was designed to amplify MAP4 cDNAs encoding the microtubule-binding domain. The lane "Markers" shows molecular weight markers $(\lambda / E$ coR $\mathrm{I}+$ HindIII double digest). The mobilities of the PCR products encoding the entire microtubule-binding domain of MAP4-LP and MAP4-SP are shown by arrows labeled with "LP" and "SP". 


\section{Repeat region organization of MAP4-SP}

We then checked whether bovine MAP4-SP contains variable Repeat regions. Using primer set \#3 (Fig. 1a), cDNAs encoding the MAP4 microtubule-binding domain were amplified. Two PCR products were clearly detected (Fig. $3 \mathrm{c}$ ). The upper band showed a molecular mass similar to that of the PCR product encoding the intact microtubulebinding domain. The lower molecular mass band (ca. 1500 bp) was considered to contain PCR products with deletions in the Pro-rich region and/or the Repeat region. We subcloned the lower molecular mass band and obtained two clones. Sequencing revealed that both encoded the microtubule-binding domain of MAP4-SP, with five AP sequences in the Repeat region: The sequence was identical to that of bovine MAP4 (Tokuraku et al., 2003), except for the 72amino acid deletion in the Pro-rich region. This result indicated that the MAP4-SP with five AP sequences was the predominant species containing a deletion in the micro-
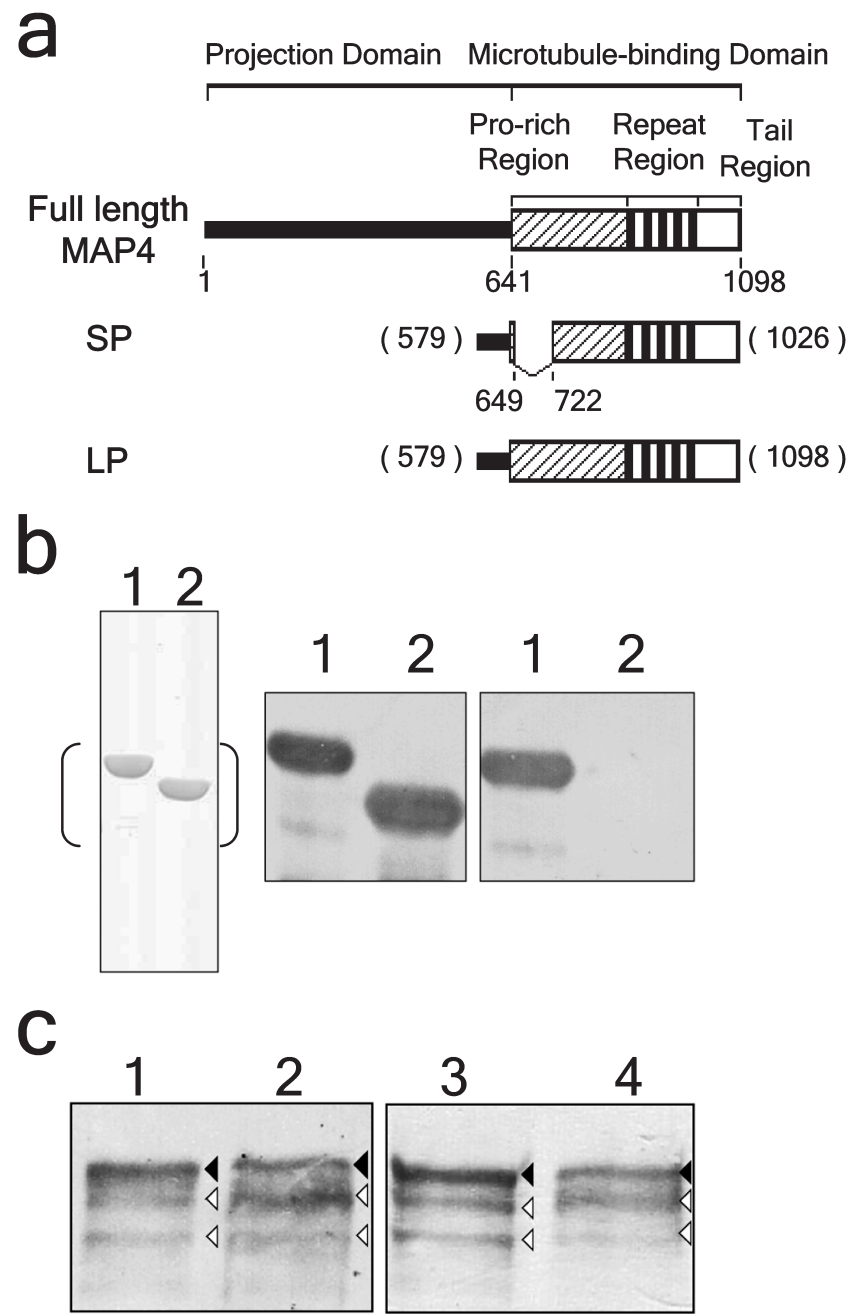

Fig. 4. tubule-binding domain. Since no other lower molecular mass bands were detected, the content of mRNAs encoding MAP4-SP with three or four AP sequences was likely to be very low, if any existed.

\section{Detection of the bovine MAP4-SP polypeptide in the adrenal medulla extract}

For further analyses, we generated two recombinant fragments (the SP fragment, containing the microtubule-binding domain of MAP4-SP with five AP sequences; and the LP fragment, containing the microtubule-binding domain of the MAP4-LP with five AP sequences (Tokuraku et al., 2003)), and their schematic primary structures are illustrated, together with that of the entire MAP4, in Fig. 4a. We first checked whether the MAP4-SP polypeptide is expressed in the bovine tissues by immunoblotting. The anti-(Pro-rich region) antiserum, which was raised against the entire Prorich region of bovine MAP4, reacted to both recombinant $\mathrm{SP}$ and LP fragments (Fig. 4b center panel). After preabsorption of the antiserum with the SP fragment, as described in Materials and Methods, the pre-absorbed anti(Pro-rich region) antiserum still reacted to the LP fragment, but failed to recognize the SP fragment (Fig. $4 \mathrm{~b}$ right panel).

When the adrenal extracts were immunoblotted with the anti-(Pro-rich region) antiserum, at least three bands were observed in both samples (Fig. 4c left panel). The highest

Fig. 4. Immunodetection of the MAP4-SP polypeptide. a, schematic structures of full length MAP4 (residues 1-1098, according to the numbering in the Refs. (Tokuraku et al., 2003) and (Aizawa et al., 1990)), the SP fragment (residues 579-1026), and the LP fragment (residues 579-1098). Arabic numerals below the figures are the amino acid residue numbers. The projection domain, the Pro-rich region, the AP sequences of 18 amino acid residues in the Repeat region, and the Tail region are indicated by a filled thin box, a shaded thick box, filled thick boxes, and an open thick box, respectively. The 72 amino acid deletion in the SP fragment starts from amino acid number 650 and ends at 721 . The $\mathrm{N}$-terminal and $\mathrm{C}$-terminal amino acid residue numbers are indicated by the numbers in parentheses on both sides of each fragment. b, immunoreaction with the LP (lane 1) and SP fragments (lane 2) using antisera. Purified LP and SP fragments (left panel, SDS-PAGE) were immunoblotted using anti-(Pro-rich region) antiserum (center panel) or the anti-(Pro-rich region) antiserum after preabsorption with the SP fragment (right panel). In each panel, lane 1 and lane 2 are the LP fragment and the SP fragment, respectively. Only the magnified view of the region indicated by parentheses in the left panel is presented in center and right panels. After the pre-absorption of the antiserum with the SP fragment, as described in the "Materials and Methods", the antiserum reacted with the LP (right panel, lane 1) but failed to recognize the SP fragment (right panel, lane 2). c, the heat-stable fractions of the bovine adrenal cortex (lanes 1 and 3) and medulla (lanes 2 and 4) were immunoblotted with the anti-(Pro-rich region) antiserum (lanes 1 and 2), and with the pre-absorbed anti-(Pro-rich region) antiserum (lanes 3 and 4). The highest molecular mass band (that was considered to be the full-length MAP4) is indicated by closed arrowheads, and two prominent lower molecular mass bands (that may be degradation products of the full-length MAP4 and/or MAP4 isoforms) are indicated by open arrowheads. 
molecular mass band should be the conventional full-length MAP4, while the others may contain MAP4 isoforms and/or degradation products of the full-length MAP4. The middle band was relatively abundant in the medulla (compare lanes 1 and 2). When the pre-absorbed anti-(Pro-rich region) antiserum was used, the band patterns remained similar in the cortex samples (lanes 1 and 3), while a marked change was observed in the medulla samples (lanes 2 and 4): The amount of the middle molecular mass band decreased (lane 4 ). The change is apparent when the intensities of the upper band and the middle band are compared in lanes 2 and 4 . Since the pre-absorbed antiserum was unable to recognize the MAP4-SP, and the MAP4-SP polypeptide would be present only in the medulla extract, as a protein band with a molecular mass slightly lower than that of intact MAP4, the blotting results strongly support the expression of the MAP4-SP polypeptide in the bovine adrenal medulla.

\section{Analysis of the interaction between the MAP4-SP fragment and microtubules}

We have previously shown that the fragment containing the entire microtubule binding domain retains properties similar to those of the intact MAP4, in terms of microtubule binding, assembly stimulation, etc. (Tokuraku et al., 1999a), and have reported the in vitro properties of various microtubulebinding domain fragments (Katsuki et al., 1999; Aizawa et al., 1991). Likewise, in this study we compared the in vitro functions of the SP fragment and the LP fragment, instead of the full-length MAP4-SP and LP. These fragments were purified to near homogeneity (Fig. 4b left panel).

We first checked whether the deletion within the Pro-rich region affected the binding affinity of the fragments to microtubules, using the taxol-stabilized microtubule system (Tokuraku et al., 1999a). Although in this procedure, taxol reportedly interferes with the proper incorporation of MAP molecules into the microtubule lattice (Kar et al., 2003), we used this method to detect the activity differences among the fragments as compared with our previous studies (Tokuraku et al., 1999a, 2003). The dissociation constant $K_{d}$ and the stoichiometry between the MAP4 fragments and tubulin protomer ${ }^{2}$ (Table I) were calculated from the Scatchard plot (data not shown). A two-fold higher binding affinity of the LP fragment over that of the SP fragment was found, whereas the binding stoichiometries of the two fragments were 0.8 and 0.9 ; both were most reasonably interpreted as 1:1 stoichiometry, as reported for other fragments (Tokuraku et al., 1999a, 2003; Coffey and Purich, 1995; Coffey et al., 1994).

Next, the microtubule assembly-promoting activity of the two fragments was measured. When various concentrations of the SP fragment were mixed with $10 \mu \mathrm{M}$ tubulin and incubated at $37^{\circ} \mathrm{C}$ under taxol-free conditions, time-dependent increases in turbidity were observed (Fig. 5a). The SP fragment possessed the assembly-promoting activity,
Table I. $K_{d}$ AND STOIHIOMETRY OF BINDING OF THE MAP4 FRAGMENTS TO TAXOL-STABILIZED MICROTUBULES

\begin{tabular}{lll}
\hline Fragment name & LP & SP \\
\hline$K d[\mu \mathrm{M}]$ & 0.14 & 0.28 \\
Stoichiometry & 0.8 & 0.9 \\
\hline
\end{tabular}

a The dissociation constant $K d(\mu \mathrm{M})$ and the stoichiometry were calculated from the Scatchard plot (data not shown) by the method of Scatchard (1949).

although the turbidity values differed from those of the LP fragment under the same conditions (Fig. 5b). When the amount of polymerized tubulin was measured directly by the sedimentation assay, the activity difference parallel to the turbidity data was not observed (compare Fig. 5b with c). The turbidity difference between the two fragments (Fig. 5b) was considered to result from features other than the amount of assembled microtubules. Meanwhile, we noticed a slight difference in the assembly promoting activity (Fig. $5 \mathrm{c})$. In the low concentration range $(0.5 \mu \mathrm{M}$ of the fragments), the difference was especially significant: The amount of assembled microtubules in the presence of the LP fragment was 1.5 times higher than that in the presence of the SP fragment at $0.5 \mu \mathrm{M}$ of each fragment, while it was only 1.1 times at the concentration of $1.5 \mu \mathrm{M}$. The critical concentration for microtubule assembly in the presence of the LP fragment was $0.13 \mu \mathrm{M}$, while that of the SP fragment was $0.25 \mu \mathrm{M}$.

We previously observed the initial stage of microtubule assembly by electron microscopy, and found that the presence of the Pro-rich region enhances the microtubule nucleating activity of the MAP4 fragments (Tokuraku et al., 2003). Using the same method, we then checked whether the deletion within the Pro-rich region affected the microtubule nucleating activity; however, there was no detectable difference in this activity between the two fragments (data not shown).

We observed the assembled structures by electron microscopy (Fig. 6). Although the microtubules in the two samples exhibited normal morphology (single wall microtubules with an outer diameter of $25 \mathrm{~nm}$ ) (Fig. 6a, and b), microtubule bundles were sometimes observed in the samples of the LP fragment (Fig. 6a, arrowhead), yet no bundles were seen in the SP fragment samples (Fig. 6b). Even at elevated concentrations $(15 \mu \mathrm{M}$ of tubulin and 15 $\mu \mathrm{M}$ of each MAP4 fragment), no bundles were observed in the SP fragment samples (data not shown). The absence of microtubule bundles in the SP fragment samples may result in their low turbidity (Fig. 5b). One possible interpretation of the morphology difference is that the LP fragment has two binding sites for microtubules and is able to bind to two different filaments, whereas the SP fragment may lack one of them and consequently does not cause bundling. However, we have already shown the 1:1 binding stoichiometry for both fragments (Table I). Previous quantitative results 

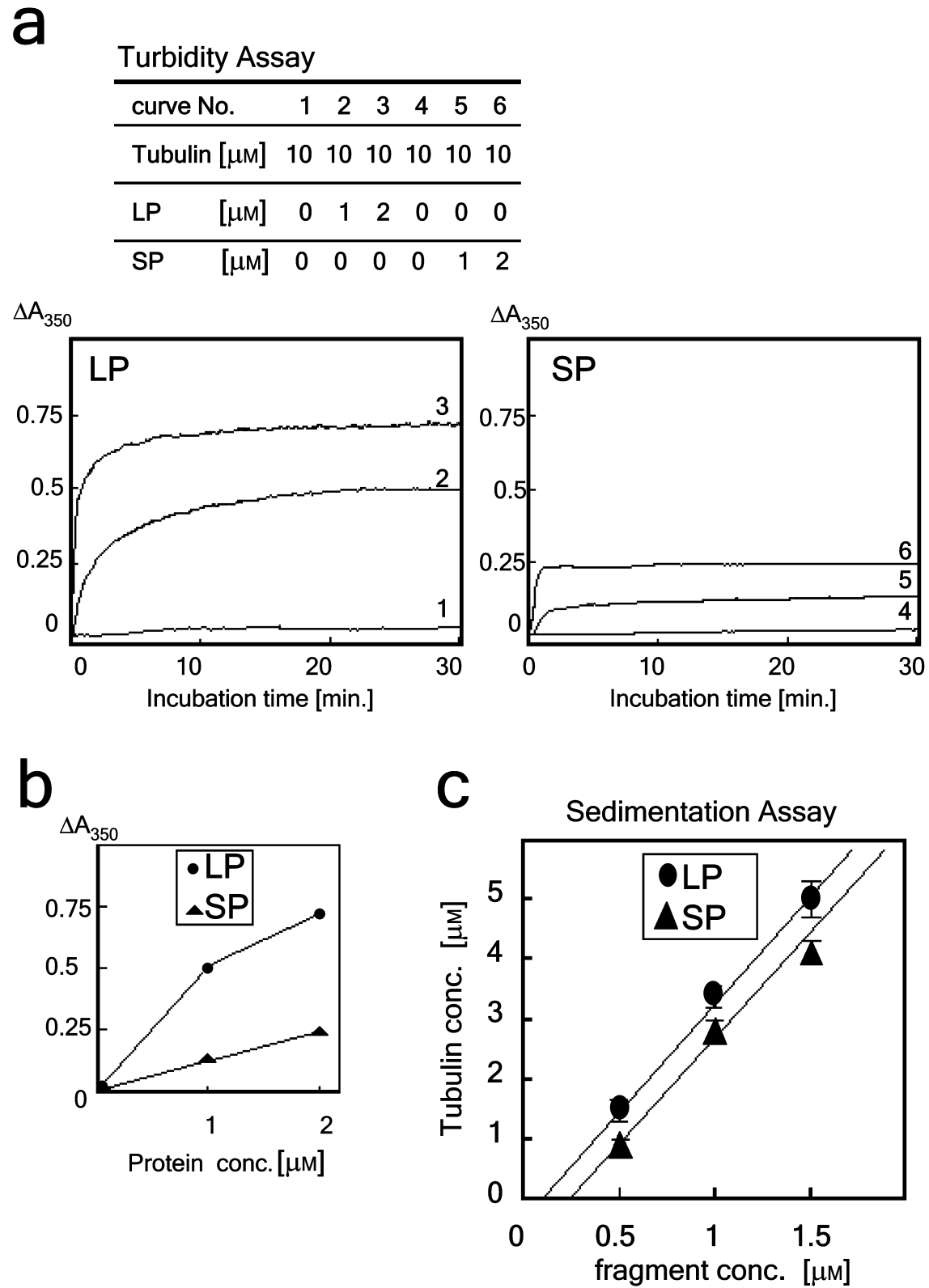

Fig. 5. Assembly-promoting activity of the SP and LP fragments. a, microtubule assembly in the presence of the MAP4 fragments was monitored by the changes in absorbance at $350 \mathrm{~nm}$. Tubulin $(10 \mu \mathrm{M})$ was mixed with the LP fragment (curve 1, $0 \mu \mathrm{M} ;$ curve 2, $1 \mu \mathrm{M} ;$ curve 3, $2 \mu \mathrm{M})$ or with the SP fragment (curve 4, $0 \mu \mathrm{M}$; curve 5, $1 \mu \mathrm{M}$; curve $6,2 \mu \mathrm{M}$ ). Tubulin polymerization was started by raising the temperature from $0{ }^{\circ} \mathrm{C}$ to $37^{\circ} \mathrm{C}$. $\mathrm{b}$, the turbidities after 10 minutes of polymerization, derived from panel a, are plotted as a function of the MAP4 fragment concentration: the LP fragment (circles) and SP fragment (triangles). c, amounts of assembled microtubules in the presence of the MAP4 fragments, measured by the sedimentation assay. Various concentrations of the MAP4 fragments and $10 \mu \mathrm{M}$ of tubulin were mixed at $0^{\circ} \mathrm{C}$ and incubated at $37^{\circ} \mathrm{C}$ for $30 \mathrm{~min}$, and the assembled microtubules were collected by centrifugation. The concentrations of polymerized tubulin were determined as described (Tokuraku et al., 1999a). The concentrations of polymerized tubulin are plotted against the concentrations of added LP (closed circles) and SP (closed triangles) fragments. The data are the averages of three independent experiments. Error bars indicate the standard errors.

using the MAP4 fragment (Tokuraku et al., 2003; Iida et al., 2002) also contradicted the idea that the MAP4 microtubule-binding domain has dual binding sites. Furthermore, we checked whether the region encoded by "exon 10" retains microtubule-binding ability, using a recombinant fragment corresponding to amino acid residues 579-717 of MAP4-LP (data not shown). The fragment hardly bound to taxol-stabilized microtubules, in spite of its highly positive charge. At present, we have no evidence that supports the dual binding site theory. 

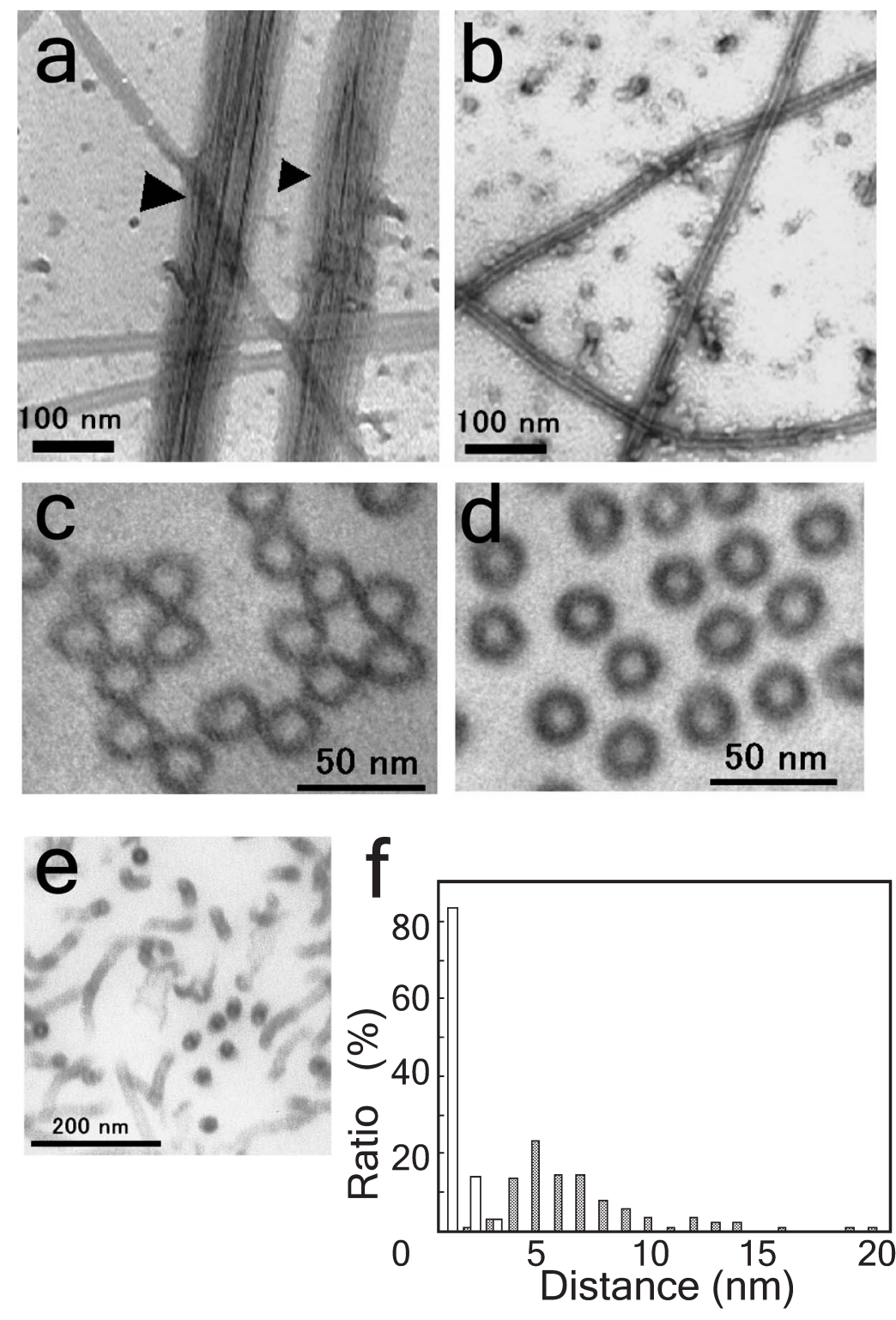

Fig. 6. Electron micrographs of microtubules reconstituted in the presence of LP or SP fragments. a and b, observations of negatively stained microtubules. $1 \mu \mathrm{M}$ of the LP (a) or SP (b) fragment and $10 \mu \mathrm{M}$ of tubulin were mixed at $0^{\circ} \mathrm{C}$ in $100 \mathrm{MEM}$ buffer containing $0.5 \mathrm{mM}$ GTP, and incubated at $37^{\circ} \mathrm{C}$ for $10 \mathrm{~min}$. Arrowheads indicate microtubule bundles. Scale bar is $100 \mathrm{~nm} . \mathrm{c}, \mathrm{d}$, and e, observations of thin sectioned microtubules. Sample solutions containing $15 \mu \mathrm{M}$ of each MAP4 isoform fragment (the LP (c) and the SP (d) fragments) and $15 \mu \mathrm{M}$ of tubulin, or $15 \mu \mathrm{M}$ of tubulin alone in the presence of taxol (e), were incubated at $37^{\circ} \mathrm{C}$ for $10 \mathrm{~min}$, and the solutions were centrifuged. Thin sectioned samples were prepared from the pellets. Scale bars are $50 \mathrm{~nm}$ for $\mathrm{c}$ and $\mathrm{d}$, and $200 \mathrm{~nm}$ for e. f, nearest neighbor distances between microtubules assembled in the presence of the LP [open bar] or SP [closed bar] fragment. The inter-microtubule distances were determined for more than 200 microtubule pairs, as described in the "Materials and Methods".

For a detailed examination, the microtubules were collected by centrifugation, and observed by ultrathin section electronmicroscopy (Fig. 6c, and d). To rule out the possibility that the small difference in the binding affinities (Table I) influenced the bundle formation, the concentrations of the MAP fragments were set at $15 \mu \mathrm{M}$, so that the surface of the microtubules would be saturated by the fragments. As expected, the microtubules in the LP fragment samples were linked to other microtubules, while the microtubules in the SP fragment samples were not. Microtubules assembled in the presence of taxol without any added MAPs are shown as a control (Fig. 6e). The control microtubules were wavy and oriented randomly. They were neither bundled nor consistently spaced, presumably because of the negative surface charges of microtubules. When the MAP4 fragments were present, the charges were neutralized by the 
positive charges of the MAP4 Repeat region, and the microtubules became bundled (Fig. 6c). These features are consistent with our previous observations (Tokuraku et al., 2003) and those of others (Iida et al., 2002). The bundling pattern in the LP fragment samples was similar to that described in our previous report (Tokuraku et al., 2003). More than 200 independent microtubule pairs were chosen at random, as described in Materials and Methods, and the inter-microtubule distances in the LP and SP fragment samples were measured (Fig. 6f). Almost all of the microtubules in the LP fragment samples were linked to the neighboring microtubule: No microtubules that were more than $4 \mathrm{~nm}$ apart from their nearest neighbors were observed. On the other hand, the microtubules polymerized in the presence of the SP fragment were not linked to other microtubules. The histogram showed a single peak at around $5 \mathrm{~nm}$, suggesting that the microtubules were constantly spaced. We also determined the inter-microtubule distance by the method of Iida et al. (Iida et al., 2002). Since their method is easier, although less precise, we measured the distances of more than 300 microtubule pairs and obtained similar results (data not shown). Bundling is a general feature of microtubules assembled in the presence of the MAP4 microtubule-binding domain fragments (Tokuraku et al., 2003; Iida et al., 2002), but the SP fragment seemed to suppress the bundling.

\section{Discussion}

In this study, we demonstrated for the first time that bovine and rat MAP4 have a naturally occurring alternatively spliced variant, MAP4-SP (MAP4 with a short Pro-rich region), which lacks 72 consecutive amino acid residues within the Pro-rich region. Since the MAP4-SP transcript is only expressed in the adrenal medulla and brain, and its expression was augmented with the neural differentiation of the PC12 cells, this isoform may be associated with neural cell activities. The deletion within the Pro-rich region slightly affected the in vitro activity of MAP4 to promote microtubule assembly, and it reduced the microtubule bundling ability of the recombinant fragment.

Since the nucleotide sequence of the subdomain missing in MAP4-SP and that of the human MAP4 exon 10 matched well, we tentatively named it "exon 10". As expected, bovine versions of the introns were located upstream and downstream of "exon 10", and the 5' donor and 3' acceptor splice sites of the bovine introns contained the dinucleotide pair GT-AG commonly associated with splicing. The rat version of the MAP4-SP transcript was also detected in this study, so it is possible that similar alternative splicings occur in human and other mammalian cells and tissues. We noted that the missing subdomain encoded by "exon 10" contains $30 \%$ of the Pro-rich region. In addition, the amino acid residues corresponding to "exon 10" were highly con- served ( $>85 \%$ amino acid identity/similarity) among the bovine, human, mouse and rat versions, whereas the conservation of the other part of the Pro-rich region (amino acid residues $641-649$ and $722-880$ in bovine MAP4) was relatively low ( $<65 \%$ amino acid identity/ similarity). This suggests the evolutional, and perhaps functional, significance of the subdomain.

The most interesting finding in this study is the cell typespecific expression of MAP4-SP. MAP4, as well as its variant, is ubiquitously expressed in many types of cells and tissues (Tokuraku et al., 2003; Chapin et al., 1995; Aizawa et al., 1990; Bulinski and Borisy, 1980; Parysek et al., 1984), whereas MAP4-SP was only detectable in the adrenal medulla and brain. We also observed that the expression level of the rat MAP4-SP transcript became slightly elevated in PC12 cells by NGF stimulation, which is a characteristic of many neuron-specific genes induced during neuronal differentiation (Yamagata et al., 1994). MAP4-SP may have some advantages over MAP4-LP in the neural cells, where the neural MAPs (MAP1, MAP2, and Tau) are abundant.

The Pro-rich region (residues 641-880; Pro, 19\%), which occupies over half of the microtubule-binding domain, is defined as a region with a high proline content on the amino-terminal side of the Repeat region in the MAP4 microtubule-binding domain (Aizawa et al., 1990). We found that the ability of the Pro-rich region to bind to microtubules is the highest among the microtubule-binding subdomains (Katsuki et al., 1999) and that this subdomain is indispensable for nucleating microtubules (Tokuraku et al., 1999a). Consequently, a decline in these activities was expected as a result of the deletion. On the one hand, we did observe slight reductions in the activities. The binding affinity of the SP fragment was lower than that of the LP fragment (Table I), and a difference in the assembly promoting activity was evident in the low concentration range (Fig. $5 c)$. The critical concentration for microtubule assembly in the presence of the SP fragment was slightly higher than that of the LP fragment (Fig. 5c). Since the cellular MAP concentration is considered to be low, these subtle differences may be physiologically significant. The deletion in the Pro-rich region may make brain MAP4 less potent in developing microtubule networks, rendering more plasticity to neuronal cells during outgrowth. The activity difference was so subtle that the hypothesis based on the difference requires further experiments using full-length LP and SP. On the other hand, another possible interpretation is that this difference in the activity becomes negligible when the large scale $(30 \%)$ reduction in the Pro-rich region is taken into account. This level of difference in the $K_{d}$ values (Table I) could be generated by structural changes in other parts of the MAP molecule, outside the microtubule-binding domain, as we have discussed elsewhere (Tokuraku et al., $2003)$, and the difference in the assembly promoting activity in the high concentration range $(1.5 \mu \mathrm{M})$ was not so striking 
(Fig. 5c). In this interpretation, the deleted part is dispensable for the microtubule binding and assembly promoting activities of the MAP molecule. Although the entire Prorich region and the Repeat region have been considered as the "microtubule binding domain", the exact portion required for a MAP molecule to interact with microtubules may be located in a more restricted region. It is possible that the deleted part (N-Pro region) possesses functions other than microtubule-binding, while the remaining carboxyl part of the Pro-rich region (C-Pro region) is responsible for the microtubule-binding activities; namely, the Pro-rich region can be further divided into functionally distinct domains. Consistent with this view, the $15 \mathrm{kDa}$ fragment of bovine MAP4 (Aizawa et al., 1989), which contains parts of the Pro-rich and Repeat regions (amino acid residues 788905, see (Aizawa et al., 1990)) reportedly retains high affinity for microtubules.

The difference in the in vitro activities between the LP and SP fragments was most remarkably observed in microtubule bundle formation. Although we previously described the differences in the bundle-forming activities among several MAP4 isoforms (Tokuraku et al., 2003), the aspect in this study was different. The microtubule bundles formed by the MAP4 isoform fragments with different Repeat region organizations differed quantitatively: bundles were observed for only $20 \%$ of the microtubules assembled by the three repeat fragment (termed $\mathrm{PA}_{3} \mathrm{~T}$ fragment), while more than $80 \%$ of the microtubules induced by the five repeat fragment (termed LP fragment in this study) were bundled (Tokuraku et al., 2003). In contrast, the differences in the bundle-forming activity of the LP fragment and that of the SP fragment were qualitative: although the SP fragment has a net charge quite similar to that of the $\mathrm{PA}_{3} \mathrm{~T}$ fragment, no bundles were observed in the SP fragment samples (Fig. 6d, and f). The simplest interpretation of this result is that the LP fragment has two microtubule binding sites, while the SP fragment lacks one of them. As described in the Results section, however, there is no basis at present to suppose that the MAP4 microtubule-binding domain has dual binding sites. The microtubules assembled by the SP fragment were consistently spaced, with an average distance of about 5.5-6.0 $\mathrm{nm}$. There may be a regulatory mechanism that controls the spacing between microtubules. We would rather consider that the SP fragment acquired a new function to space microtubules.

Iida et al. (2002) measured the nearest neighbor distance between microtubules reassembled in vitro with intact human MAP4 or a MAP4 fragment with a deletion in the projection domain (called Na-PJ2). The mean inter-microtubule distances were 10-12.5 and 7.5-10 nm, respectively. They proposed that the distances were dependent on the lengths of the projection domains. The distance between the microtubules induced by the SP fragment was $5.5-6.0 \mathrm{~nm}$ (Fig. 6f). According to their theory, this can be explained by supposing that the N-terminal portion of the SP fragment protrudes from the microtubule surface and serves as a spacer. About 70 amino acid residues of the SP fragment N-terminus (starting from 579 to the splice junction in the Pro-rich region (649), Fig. 4a), may be responsible for the activity. The question remains: why does the corresponding portion of the LP fragment fail to show the same effect? The microtubules induced by the LP fragment were tightly bound to each other, with little space in between. In the SP fragment, the deletion of the N-Pro region may lead to a conformational change in the amino terminal part when the fragment binds to the microtubule, resulting in a constant distance between microtubules. The N-Pro region may suppress the conformational change in the LP fragment. It is also possible that the N-Pro region and/or a regulatory protein that binds to the region may convert one conformational state to another in the full-length MAP4-LP.

The highly conserved sequence of the N-Pro region suggests that it serves as an interaction site for molecules or organelles that have yet to be identified. The plausible candidates are microtubule-dependent motor proteins, or other cellular microtubule-related enzymes. Previously, the p34 ${ }^{\mathrm{cdc} 2}$ kinase/cyclin B complex was reported to associate with microtubules through MAP4 (Ookata et al., 1995), and two phosphorylation sites were identified in the Pro-rich region (Ookata et al., 1997). Although MAP4-SP contains these two corresponding sites (Fig. 1c) in spite of the deletion of the N-Pro region, this subdomain may be critical for the interaction with $\mathrm{p} 34^{\mathrm{cdc} 2}$ kinase/cyclin B and/or for the efficiency of the phosphorylation. In this study, the microtubule-binding domain of a cell type-specific MAP4 variant, MAP4-SP, has been characterized in vitro. The functions of MAP4-SP in the neural cells await further analyses.

Acknowledgments. This research was financially supported in part by the Sasagawa Scientific Research Grant from the Japan Scientific Society. We wish to thank Dr. N. Lomax, of the Natural Products Branch, National Cancer Institute, Bethesda, MD, USA, for providing the taxol. Thanks are also due to Dr. Brenda Guthrie (SKYBAY Scientific Editing) for reading the manuscript.

\section{References}

Aizawa, H., Kawasaki, H., Murofushi, H., Kotani, S., Suzuki, K., and Sakai, H. 1989. A common amino acid sequence in 190-kDa microtubule-associated protein and tau for the promotion of microtubule assembly. J. Biol. Chem., 264: 5885-5890.

Aizawa, H., Emori, Y., Murofushi, H., Kawasaki, H., Sakai, H., and Suzuki, K. 1990. Molecular cloning of a ubiquitously distributed microtubule-associated protein with Mr 190,000. J. Biol. Chem., 265: 1384913855 .

Aizawa, H., Emori, Y., Murofushi, H., Mori, A., Murofushi, H., Sakai, H., and Suzuki, K. 1991. Functional analyses of the domain structure of microtubule-associated protein-4 (MAP-U). J. Biol. Chem., 266: 98419846

Andreadis, A., Brown, W.M., and Kosik, K.S. 1992. Structure and novel exons of the human tau gene. Biochemistry, 31: 10626-10633.

Bulinski, J.C. and Borisy, G.G. 1980. Widespread distribution of a $210,000 \mathrm{~mol} \mathrm{wt}$ microtubule-associated protein in cells and tissues of primates. J. Cell Biol., 87: 802-808. 
Chapin, S.J., Lue, C.M., Yu, M.T., and Bulinski, J.C. 1995. Differential expression of alternatively spliced forms of MAP4: a repertoire of structurally different microtubule-binding domains. Biochemistry, 34: 22892301.

Chomczynski, P. and Sacchi, N. 1987. Single-step method of RNA isolation by acid guanidinium thiocyanate-phenol-chloroform extraction. Anal. Biochem., 162: 156-159.

Coffey, R.L., Joly, J.C., Cain, B.D., and Purich, D.L. 1994. Exploring the microtubule-binding region of bovine microtubule-associated protein-2 (MAP-2): cDNA sequencing, bacterial expression, and site-directed mutagenesis. Biochemistry, 33: 13199-13207.

Coffey, R.L. and Purich, D.L. 1995. Non-cooperative binding of the MAP-2 microtubule-binding region to microtubules. J. Biol. Chem., 270: 10351040.

Drubin, D.G., Caput, D., and Kirschner, M.W. 1984. Studies on the expression of the microtubule-associated protein, tau, during mouse brain development, with newly isolated complementary DNA probes. $J$. Cell Biol., 98: 1090-1097.

Dustin, P. 1984. Microtubules, 2nd edn. Springer-Verlag, Heidelberg, Berlin. Goedert, M., Wischik, C.M., Crowther, R.A., Walker, J.E., and Klug, A. 1988. Cloning and sequencing of the cDNA encoding a core protein of the paired helical filament of Alzheimer disease: identification as the microtubule-associated protein tau. Proc. Natl. Acad. Sci. USA, 85: 4051-4055.

Himmler, A., Drechsel, D., Kirschner, M.W., and Martin, D.W. Jr. 1989. Tau consists of a set of proteins with repeated C-terminal microtubulebinding domains and variable N-terminal domains. Mol. Cell Biol., 9: 1381-1388.

Iida, J., Itoh, T.J., Hotani, H., Nishiyama, K., Murofushi, H., Bulinski, J.C., and Hisanaga, S. 2002. The projection domain of MAP4 suppresses the microtubule-bundling activity of the microtubule-binding domain. $J$. Mol. Biol., 320: 97-106.

Jacob, M. and Gallinaro, H. 1989. The 5' splice site: phylogenetic evolution and variable geometry of association with U1RNA. Nucleic Acids Res., 17: 2159-2180.

Kalcheva, N., Albala, J., O'Guin, K., Rubino, H., Garner, C., and ShafitZagardo, B. 1995. Genomic structure of human microtubule-associated protein 2 (MAP-2) and characterization of additional MAP-2 isoforms. Proc. Natl. Acad. Sci. USA, 92: 10894-10898.

Kar, S., Fan, J., Smith, M.J., Goedert, M., and Amos, L.A. 2003. Repeat motifs of tau bind to the insides of microtubules in the absence of taxol. EMBO J., 22: 70-77.

Katsuki, M., Tokuraku, K., Murofushi, H., and Kotani, S. 1999. Functional analysis of microtubule-binding domain of bovine MAP4. Cell Struct. Funct., 24: 337-344.

Katsuki, M., Tokuraku, K., Nakagawa, H., Murofushi, H., and Kotani, S. 1997. The 'assembly-promoting sequence region' of microtubuleassociated protein 4 failed to promote microtubule assembly. FEBS Lett., 418: $35-38$.

Kindler, S., Schulz, B., Goedert, M., and Garner, C.C. 1990. Molecular structure of microtubule-associated protein $2 \mathrm{~b}$ and $2 \mathrm{c}$ from rat brain. $J$. Biol. Chem., 265: 19679-19684.

Kotani, S., Murofushi, H., Maekawa, S., Sato, C., and Sakai, H. 1986. Characterization of microtubule-associated proteins isolated from bovine adrenal gland. Eur. J. Biochem., 156: 23-29.

Laemmli, U.K. 1970. Cleavage of structural proteins during the assembly of the head of bacteriophage T4. Nature, 277: 680-685.

Lazo, P.A. 1988. Rearrangement of both alleles of human chromosome 8 in HeLa cells, one of them as a result of papillomavirus DNA integration. J. Biol. Chem., 263: 360-367.

Lee, G., Cowan, N., and Kirschner, M. 1988. The primary structure and heterogeneity of tau protein from mouse brain. Science, 239: 285-288.

Lewis, S.A., Wang, D.H., and Cowan, N.J. 1988. Microtubule-associated protein MAP2 shares a microtubule binding motif with tau protein
Science, 242: 936-939.

Lowry, O.H., Rosebrough, N.J., Farr, A.L., and Randall, R.J. 1951. Protein measurement with the folin phenol reagent. J. Biol. Chem., 193: 265-275.

Nakagawa, H., Yoshida, M., and Miyamoto, S. 2000. Nitric oxide underlies the differentiation of $\mathrm{PC} 12$ cells induced by depolarization with high KCl. J. Biochem., 127: 113-119.

Nakagawa, H. and Miyamoto, S. 1998. Actin-filaments localize on the sorting endosomes of 3 Y 1 fibroblastic cells. Cell Struct. Funct., 23: 283-290.

Ookata, K., Hisanaga, S., Bulinski, J.C., Murofushi, H., Aizawa, H., Itoh, T.J., Hotani, H., Okumura, E., Tachibana, K., and Kishimoto, T. 1995. Cyclin B interaction with microtubule-associated protein 4 (MAP4) targets p34cdc2 kinase to microtubules and is a potential regulator of M-phase microtubule dynamics. J. Cell Biol., 128: 849-862.

Ookata, K., Hisanaga, S., Sugita, M., Okuyama, A., Murofushi, H., Kitazawa, H., Chari, S., Bulinski, J.C., and Kishimoto, T. 1997. MAP4 is the in vivo substrate for CDC2 kinase in HeLa cells: identification of an M-phase specific and a cell cycle-independent phosphorylation site in MAP4. Biochemistry, 36: 15873-15883.

Parysek, L.M., Asnes, C.F., and Olmsted, J.B. 1984. MAP 4: occurrence in mouse tissues. J. Cell Biol., 99: 1309-1315.

Sambrook, J., Fritsch, E.F., and Maniatis, T. 1989. Molecular Cloning: A Laboratory Manual, 2nd edn. Cold Spring Harbor Laboratory, Cold Spring Harbor, NY.

Sanger, F., Nicklen, S., and Coulson, A.R. 1977. DNA sequencing with chain-terminating inhibitors. Proc. Natl. Acad. Sci. USA, 74: 5463-5467.

Scatchard, G. 1949. The attractions of proteins for small molecules and ions. Ann. NY Acad. Sci., 51: 660-672.

Shelanski, M.L., Gaskin, F., and Cantor, C.R. 1973. Microtubule assembly in the absence of added nucleotides. Proc. Natl. Acad. Sci. USA, 70: 765-768.

Tokuraku, K., Katsuki, M., Nakagawa, H., and Kotani, S. 1999a. A new model for microtubule-associated protein (MAP)-induced microtubule assembly. The Pro-rich region of MAP4 promotes nucleation of microtubule assembly in vitro. Eur. J. Biochem., 259: 158-166.

Tokuraku, K., Katsuki, M., Matui, M., Kuroya, T., and Kotani, S. 1999b. Microtubule-binding property of microtubule-associated protein 2 differs from that of microtubule-associated protein 4 and tau. Eur. J. Biochem., 264: 996-1001.

Tokuraku, K., Katsuki, M., and Kotani S. 2002. Structural and functional analyses of microtubule-associated protein 4. Recent Res. Devel. Biochem., 3: 315-333.

Tokuraku, K., Matsushima, K., Matui, T., Nakagawa, H., Katsuki, M., Majima, R., and Kotani, S. 2003. The number of repeat sequences in microtubule-associated protein 4 affects the microtubule surface properties. J. Biol. Chem., 278: 29609-29618.

Weingarten, M.D., Lockwood, A.H., Hwo, S.Y., and Kirschner, M.W. 1975. A protein factor essential for microtubule assembly. Proc. Natl. Acad. Sci. USA, 72: 1858-1862.

West, R.R., Tenbarge, K.M., and Olmsted, J.B. 1991. A model for microtubule-associated protein 4 structure. Domains defined by comparisons of human, mouse, and bovine sequences. J. Biol. Chem., 266: 2188621896.

Yamagata, K., Sanders, L.K., Kaufmann, W.E., Yee, W., Barnes, C.A., Nathans, D., and Worley, P.F. 1994. Rheb, a growth factor- and synaptic activity-regulated gene, encodes a novel Ras-related protein. J. Biol. Chem., 269: 16333-16339.

Yoshida, H. and Goedert, M. 2002. Molecular cloning and functional characterization of chicken brain tau: isoforms with up to five tandem repeats. Biochemistry, 41: 15203-15211.

(Received for publication, November 4, 2004

and accepted, December 4, 2004) 